\title{
Seroprevalence and risk factors of Toxoplasma gondii infection in sheep and goats slaughtered for human consumption in Central Ethiopia
}

\author{
Endrias Zewdu Gebremedhin 1* Mukarim Abdurahaman², Tsehaye Hadush ${ }^{3}$ and Tesfaye Sisay Tessema ${ }^{4}$
}

\begin{abstract}
Background: Toxoplasmosis is one of the most common parasitic zoonoses worldwide. Humans get infections with T. gondii after ingesting raw or undercooked meat or oocysts via contaminated soil, food or water; or congenitally by transplacental transmission of tachyzoites. The objectives of the present study were to estimate the seroprevalence and assess risk factors for T. gondii infection in sheep and goats slaughtered for human consumption in Central Ethiopia.
\end{abstract}

Methods: A cross-sectional study was carried out from September, 2011 to November, 2012 in randomly selected small ruminants $(n=628)$. Direct Agglutination Test (DAT) was used to detect lgG antibodies specific to T. gondii. A titer of 1: 40 or 1: 4000 or both was considered indicative of T. gondii exposure. Logistic regression was used to assess potential risk factors.

Results: An overall seroprevalence of 17.68\% (111/628) (95\% confidence interval [Cl]:14.77 - 20.89) was detected. Twenty percent (61/305) seroprevalence (95\% Cl: 15.6 - 624.94) in sheep was found with a reciprocal end titers of 60 in fourteen, 180 in three, 540 in two, 1620 in five, 6000 in nine, 18000 in six, 54000 in eleven and 162000 in eleven. Similarly, seroprevalence of 15.48\% (50/323) (95\% Cl:11.71 - 19.89) in goats was found with a reciprocal end titers of 60 in eighteen, 180 in five, 540 in three, 1620 in seven, 6000 in four, 18000 in four, 54000 in five and 162000 in four. Multivariable logistic regression analysis showed that the risk of T. gondii infection was significantly higher in adult sheep (adjusted Odd ratio $(\mathrm{aOR})=2.02,95 \% \mathrm{Cl}: 1.10-3.70 ; P=0.023$ ) than in young sheep and in sheep sampled during the dry season $(\mathrm{aOR}=4.19,95 \% \mathrm{Cl}: 1.55-11.33, P=0.005)$ than those sampled during wet season.

Conclusions: The seroprevalence of T. gondii infection in small ruminants slaughtered for human consumption in Central Ethiopia is high. Age and season are significant predictors of seropositivity in sheep. The study highlighted the importance of meat of small ruminants as a potential source of infection for humans. Prevention of the spread of the disease through farm biosecurity measures is essential.

Keywords: DAT, Sheep, Goat, Toxoplasma gondii, Seroprevalence, Central Ethiopia

\footnotetext{
* Correspondence: endrias.zewdu@gmail.com

'Department of Veterinary Laboratory Technology, Faculty of Agriculture and

Veterinary Sciences Ambo University, P.O.Box 19, Ambo, Ethiopia

Full list of author information is available at the end of the article
} 


\section{Background}

Toxoplasmosis is one of the most common parasitic zoonoses world-wide caused by Toxoplasma gondii, which establishes long-lasting infections in humans and animals $[1,2]$. Toxoplasma gondii is intracellular Apicomplexan protozoan capable of infecting almost any cell type, making it one of the most 'successful' protozoan parasites on earth. Felids are the definitive hosts for $T$. gondii and warmblooded species, including humans, serve as intermediate hosts [1]. Humans get infections with $T$. gondii after ingesting raw or undercooked meat, by ingesting cat-shed oocysts via contaminated soil, food or water; or congenitally by transplacental transmission of tachyzoites. However, the clinical disease is seen only in few cases $[1,3]$ with serious consequences in pregnant women and immunocompromised patients $[1,4]$. T. gondii is also recognized as a major cause of reproductive failure in sheep, goats and pigs $[1,4,5]$. Recent reports show increasing number of evidences linking T. gondii infection with schizophrenia [6], epilepsy [7] and traffic accidents [8]. If toxoplasmosis play etiological role or attributed to the aforementioned problems then the global burden of toxoplasmosis is likely to be much higher [3] together with the life-long health care costs of congenitally infected babies. However, toxoplasmosis is still a neglected and often unreported disease despite causing a considerable global burden of ill health in humans and having a substantial financial burden on livestock industries [3].

Antibodies to T. gondii have been found worldwide in animals and humans [1]. Infection rate in meat-producing animals varies widely both within and between countries and is significantly higher in outdoor or extensively managed than indoor kept animals. Among livestock, pigs, sheep and goats have the highest rates of chronic T. gondii infection [4]. Ethiopia is among countries of the world where high occurrence of serologic evidence of $T$. gondii infection in humans [4,9], sheep, goats, cattle [10-15], cats [16] and chickens [17] have been documented from different parts of the country. Seroepidemiological assessment of infection rates due to $T$. gondii, coupled with measures taken to reduce infection at farm level through hygienic farm management practice, is best approach to reduce the risk of $T$. gondii infection for consumers [18]. Among the serological tests, Modified Agglutination Test (MAT) is the major recommended test for diagnosis of $T$. gondii in several animals and humans with the highest sensitivity among all serological tests [1] and this was confirmed by the results obtained by Shaapan et al. [19].

In view of the inadequate epidemiological data on toxoplasmosis in small ruminant slaughtered for human consumption, economic significance of small ruminants and their potential to spread toxoplasmosis to humans in Ethiopia, the present study was initiated with the objectives of estimating the seroprevalence and risk factors of
T. gondii infection in sheep and goats slaughtered for human consumption in Debre-Zeit export abattoir.

\section{Methods \\ Study animals}

The study was conducted in sheep and goats brought to an export abattoir in Debre-Zeit town from two purposively selected Zones of Central Ethiopia (East Shewa and West Shewa). The origin of the animals is mainly from Fentale, Adea (East Shewa Zone) and Ambo (West Shewa Zone) districts. In this study, few females were sampled because females are normally kept for breeding purpose and those arriving at the abattoir are culls and/or infertile animals. Sheep and goats of different breeds aged over six months were included in this study. Age was determined by observation of the erupted permanent incisors [20]. Animals' $\leq 1$ year were considered as young while those above one year were considered adult.

\section{Study design and sample size}

This cross-sectional study was carried out from September, 2011 to November, 2012. The numbers of study animals were determined based on an expected prevalence of $19.8 \%$ for goats [14], 31.6\% for sheep [13], and 5\% absolute precision using the formula described by Thrusfield [21]. Accordingly, the calculated sample sizes were 333 for sheep and 244 for goats (total $=577$ ). However, 305 sheep and 323 goats (total $=628$ animals) were randomly sampled.

\section{Blood collection}

Blood samples were collected directly from heart chambers after slaughtering, properly labeled and the sera were separated by centrifugation at 3200 RPM for 10 minutes. The extracted sera were transferred to other sterile vials and kept at $-20^{\circ} \mathrm{C}$ until serologically assayed.

\section{Serological examination}

Toxoplasma gondii-specific IgG antibodies were detected by the direct agglutination test (DAT) (Toxo screen DA, biomerieux ${ }^{\oplus}$, France) following the procedure described by manufacturer of the kit. Sera were assayed at a screening dilution of $1 / 40$ and $1 / 4000$ in order to avoid the false negative results that might happen at low dilutions when using sera with high antibody titers. A titer of 1: 40 or 1: 4000 or both was considered indicative of $T$. gondii exposure. Sedimentation of antigen at the bottom of the well and clear agglutination above half of the well at either dilutions were recorded as negative and positive results respectively. Positive and negative controls were included in each test. DAT positive samples were titrated to know the endpoint titer. 


\section{Statistical analyses}

The data generated were stored in Microsoft excel spreadsheet (Microsoft Corporation) and analyzed using STATA version 11.0 for Windows (Stata Corp. College Station, USA). Continuous data collected from abattoir for age was later on changed to categorical data for ease of handling. All the variables assessed were categorical and variables with more than two categories were transformed into indicator (dummy) variables. Seroprevalence was calculated by dividing the number of animals tested positive by the total number of animals tested. Association of risk factors (independent variables) with dependent variable (T. gondii positivity) was initially assessed using cross tabulation. Univariable logistic regression analysis was performed, and odds ratios (OR) and 95\% confidence intervals (CI 95\%) were used to quantify the strength of association between risk factors and T. gondii infection. Collinearity was assessed using collinearity matrix but none of the variables were found collinear. Variables that presented $P$-value of $<0.20$ in univariable analysis were entered in the multivariable logistic regression model. The 95\% confidence level was used and results were considered significant at $P \leq 0.05$.

\section{Ethics statement}

This research project was reviewed and approved by the ethical committee for animal experimentation of the College of Veterinary Medicine and Agriculture, Addis Ababa University, Ethiopia. All animals were handled in strict accordance with good animal practice.

\section{Results}

\section{Overall seroprevalence}

The overall seroprevalence of anti-Toxoplasma gondii IgG antibodies in small ruminants was 17.68\% (95\% confidence interval [CI]:14.77 - 20.89). Seroprevalence of $15.48 \%$ in goats (95\% CI: $11.71-19.89)$ and 20\% (95\% CI: 15.6 - 24.94) in sheep was found. The highest seropositivity was recorded from sheep of West Shewa Zone and from goats originated from East Shewa Zone (Table 1).

Thirty-four per cent of DAT positive goats have end titer of $\geq 6000(\geq 600 \mathrm{IU} / \mathrm{ml})$ while $60.7 \%$ of seropositive sheep have end titer of $\geq 6000(\geq 600 \mathrm{IU} / \mathrm{ml})$. The DAT end titer of animals found positive for the screening was depicted in Table 2.

\section{Risk factors}

\section{Goats}

Univariable analysis of the association between putative risk factors and T. gondii seropositivity in goats showed that all variables considered have no statistically significant association $(P>0.05)$.

\section{Sheep}

The seroprevalence of toxoplasmosis was significantly different between the origins of sheep in that it was higher in sheep from West Shewa Zone $(29.47 \%)$ than sheep from East Shewa Zone $(15.71 \%)(x 2=7.7397 ; P=0.005$; Table 1$)$. Univariable analysis of the association between putative risk factors and $T$. gondii seropositivity showed that sheep from West Shewa are 2.24 times more likely to be seropositive than sheep from East Shewa $(P \leq 0.05)$. In sheep, seroprevalence is higher in Horro breed than Afar breed and in dry season than wet season.

None of the factors investigated in goat are independent predictors of $T$. gondii infection while season and age were found to be independent predictors of seropositivity in sheep (Table 3).

\section{Discussion}

\section{Overall seroprevalence}

In the present study, the seroprevalence recorded in sheep (20.0\%) was found to be relatively higher than in goats (15.48\%). This is similar to the previous reports from Ethiopia [11,13-15] and Ghana [22]. This might be due to the differences in feeding habits since sheep are more likely to get infection from the pasture as they graze close to the ground than goats which prefer browsing. Higher percentage of seropositive sheep (60.7\%) had also end titer of $\geq 600 \mathrm{IU} / \mathrm{ml}$ compared to goats $(34.0 \%)$ perhaps due to more frequent infection or re-infection by the parasite in the environment. The seroprevalence recorded in sheep is in close agreement with the seroprevalence estimated in previous studies in Ethiopia [10] but lower compared to seroprevalence reports of various investigators [13,23-27]. Much higher seroprevalence in sheep than the present finding has been reported $[4,11,15,28-32]$.

Table 1 Overall IgG seroprevalence of $T$. gondii infection in sheep and goats according to study area

\begin{tabular}{|c|c|c|c|c|c|c|}
\hline \multirow[t]{2}{*}{ Study zones } & \multicolumn{2}{|c|}{ Sheep } & \multicolumn{2}{|c|}{ Goats } & \multicolumn{2}{|c|}{ Total } \\
\hline & No. tested & No. positive (\%) & No. tested & No. positive (\%) & No. tested & No. positive (\%) \\
\hline East Shewa & 210 & $33(15.71)$ & 233 & $38(16.31)$ & 443 & 71 (16.03) \\
\hline West Shewa & 95 & $28(29.47)$ & 90 & $12(13.33)$ & 185 & $40(21.62)$ \\
\hline Total & 305 & $61(20.00)^{a}$ & 323 & $50(15.48)^{b}$ & 628 & $111(17.68)^{c}$ \\
\hline
\end{tabular}

${ }^{\mathrm{a}}$ significant between zones $(P<0.05),{ }^{\mathrm{b}}$ not significant $(P>0.05),{ }^{c}$ not significant $(P>0.05)$.

The number of sheep and goats sera samples examined serologically using DAT, become positive from each study zones along with the total number of small ruminants tested and become positive. 
Table 2 DAT end titers of seropositive sheep and goats samples

\begin{tabular}{|c|c|c|c|c|c|c|c|c|c|c|}
\hline \multirow[t]{3}{*}{ Species } & \multirow[t]{3}{*}{ No. tested } & \multirow[t]{3}{*}{ No. positive } & \multicolumn{8}{|c|}{ Reciprocal DAT titers } \\
\hline & & & \multicolumn{4}{|c|}{ Positive at 1:40 } & \multicolumn{4}{|c|}{ Positive at $1: 4000$} \\
\hline & & & 60 & 180 & 540 & 1620 & 6000 & 18000 & 540000 & 162000 \\
\hline Sheep & 305 & 61 & 14 & 3 & 2 & 5 & 9 & 6 & 11 & 11 \\
\hline Goat & 323 & 50 & 18 & 5 & 3 & 7 & 4 & 4 & 5 & 4 \\
\hline Total & 628 & 111 & 32 & 8 & 5 & 12 & 13 & 10 & 16 & 15 \\
\hline
\end{tabular}

Note: According to the WHO third international standard preparation reciprocal antibody titer of 10 is equivalent to $1 \mathrm{IU} / \mathrm{ml}$, i.e., $1: 180$ is equivalent to $18 \mathrm{IU} / \mathrm{ml}$. Number of sheep and goats sera tested and number positive at screening dilutions (1:40 and 1:4000) along with DAT end titer. The numbers under each dilution indicate the number of sheep or goat samples positive at that serum dilution.

The seroprevalence recorded in goats (15.48\%) from Central Ethiopia was consistent with the result of Kassali and Teklye [10], Bisson et al. [33], Jittapalapong et al. [34], Ramzan et al. [27] and Zewdu et al. [14]. However, our result is lower than the seroprevalence reported by Demissie and Tilahun [24], Negash et al. [11], Hove et al. [28], Teshale et al. [12], Yibeltal [15] and Barakat et al. [35].

The differences in the prevalence observed between the present study and aforementioned studies could be due to differences in the relative cat densities, the access of sheep and goats to contaminated feed and water, the agro-climatic variation, the age and sex of the animals examined, the diagnostic techniques used [36,37], cut-off value and sample size [38]. The high seroprevalence in the current study could be ascribed to suitable climatic conditions, wide spread presence of cats and extensive animal production systems $[1,4,13,14]$. In the present study, identification of $T$. gondii seropositive sheep and goats was done using DAT due to its high sensitivity and specificity among all serological tests. Moreover, DAT is a major recommended test for diagnosis of toxoplasmosis in numerous species of animals and humans [1].

\section{Risk factors}

This study used samples from abattoir where the majority of the slaughtered animals are young (55.7\%, 350/ 628 ) and male $(95.9 \%, 602 / 638)$. The significantly high prevalence in adult sheep than young sheep is due to high chance of exposure to the source of infection as the age increases and suggests that most sheep acquire the infection post-natal $[1,13,15,27]$.

Table 3 Results of multivariable logistic regression analysis of risk factors and their association with $T$. gondii seropositivity

\begin{tabular}{|c|c|c|c|}
\hline Risk factors $^{a}$ & Category & Adjusted $\mathrm{OR}^{\mathrm{b}}(95 \% \mathrm{Cl})$ & P-value \\
\hline \multicolumn{4}{|c|}{ Goat } \\
\hline & Arsi-Bale & 1.00 & - \\
\hline \multirow[t]{2}{*}{ Breed } & Western highland & $1.13(0.48,2.66)$ & 0.772 \\
\hline & Afar & $1.73(0.83,3.59)$ & 0.141 \\
\hline \multirow{2}{*}{ Season } & Wet & 1.00 & - \\
\hline & Dry & $1.64(0.82,3.27)$ & 0.164 \\
\hline \multicolumn{4}{|c|}{ Sheep } \\
\hline \multirow[t]{2}{*}{ Origin } & East Shewa & 1.00 & - \\
\hline & West Shewa & $1.69(0.75,3.78)$ & 0.203 \\
\hline \multirow[t]{2}{*}{ Sex } & Male & 1.00 & - \\
\hline & Female & $3.14(0.80,12.43)$ & 0.102 \\
\hline \multirow[t]{2}{*}{ Age } & Young & 1.00 & - \\
\hline & Adult & $2.02(1.10,3.70)$ & 0.023 \\
\hline \multirow[t]{2}{*}{ Breed } & Afar & 1.00 & - \\
\hline & Arsi-Bale & $2.64(0.89,7.78)$ & 0.079 \\
\hline \multirow[t]{2}{*}{ Season } & Wet & 1.00 & - \\
\hline & Dry & $4.19(1.55,11.33)$ & 0.005 \\
\hline
\end{tabular}

${ }^{\mathrm{a}}$ The variables included to the multivariable model were those with $P \leq 0.20$ in the univariable analysis; ${ }^{\mathrm{b}}$ Odds ratio adjusted for the variables in the table, Horro breed of sheep was dropped due to collinearity with origin. The bold P-values are significant.

Factors associated with T. gondii seropositivity in study zones with their category, adjusted odds ratio (aOR) and corresponding $95 \%$ confidence interval (95\% Cl) in the final multivariable logistic regression model. 
Sheep sampled during the dry season (December to March) have four time more chance of seropositivity $(P=0.005)$ as compared to those sampled during wet season (April to November). This might be a reflection of fluctuations or differences in rate of transmission between seasons in that more infections taking place in the preceding wet months (where the climate is more suitable for survival of the oocysts) were being carried to dry season. Since IgG antibodies to $T$. gondii are long lasting in the body of the animals, the high positivity seen in dry season might partly be due to the carry over effect from preceding wet season infections (i.e. it doesn't necessarily mean that serpositive animals sampled in dry season are infected in same dry season).

Univariable logistic regression analysis showed that seroprevalence in sheep was significantly associated with study areas and breed of sheep $(P<0.05)$. However, these variables were not found to be independent predictors of seropositivity in the multivariable model. Seroprevalence in sheep of West Shewa Zone (29.47\%) was significantly higher than East Shewa Zone (15.71\%) $(P=0.006)$. This might be due to climatic differences between the two Zones. Most areas of East Shewa Zone are low land with arid and semi-arid conditions less suitable for survival of oocysts of $T$. gondii in the external environment $[13,14]$. Thus, the tenacity and infectivity of oocysts in East Shewa Zone might be less compared to West Shewa Zone. Horro breed of sheep were twice more likely to be seropositive $(\mathrm{OR}=2.16,95 \% \mathrm{CI}$ : 1.01 4.61; $P=0.047)$ compared to Afar breed of sheep. Breed difference in $T$. gondii seropositivity was unknown.

In the present study, the presence of antibodies in sheep and goats demonstrate an exposure to $T$. gondii but does not confirm or necessarily indicate that these animals are currently sources of meat borne infection to humans. This is due to the fact that some seropositive small ruminants might harbor non-viable tissue cysts. However, considerable numbers of these seropositive animals were found to harbor viable tissue cysts of $T$. gondii in edible organs (Gebremedhin et al., unpublished) thus posing potential threat to consumers. The widespread exposure of small ruminants to oocysts of T. gondii in the present study corroborates well with the high seroprevalence $(81.4 \%)$ of toxoplasmosis in women of childbearing age from the same study Zones of Central Ethiopia reported recently [39].

The over representation of male and young animals included in the present study, due to higher presentation of such groups of food animals for slaughter and subsequent export to Arabian countries, might introduce some bias in underestimating the overall seroprevalence estimate of the population of origin. Hence, the information might not be inferable to the general population. Nevertheless, the prevalence estimate could be used for assessment of risk of small ruminant meat for people.

\section{Conclusions}

The seroprevalence of $T$. gondii infection in small ruminants slaughtered for human consumption in Central Ethiopia is high. Age and season are significant predictors of seropositivity in sheep. The study highlighted the potential public health importance of meat of sheep and goats as source of infection for humans. Such prevalence studies can contribute in risk assessment of small ruminant's meat for human consumption. Prevention of the spread of the disease through farm biosecurity measures is essential.

\section{Competing interest}

The authors declare that they have no competing interests.

\section{Authors' contributions}

EZG conceived and designed the proposal, collected, tested and analyzed the data and drafted the article. MA and TA participated in sample collection, laboratory testing and drafting of article. TST participated in the study design and edition of article. All authors read and approved the final manuscript.

\section{Acknowledgements}

The financial support of Oromia Regional State Rural Capacity Building, Addis Ababa University (combating HIV/AIDS and promoting maternal and child health project), Ambo University and VLIR-UOS project no. "ZEIN 2010 PR 372 "promotion of the PhD program in Veterinary Public Health at the Faculty of Veterinary Medicine", Belgium are highly acknowledged. We are extremely indebted to Professor Dr. Bruno Goddeeris, from the Catholic University of Leuven who is leading the VLIR-UOS project, for facilitation of the overall research grant, continuous support and follow up. The authors also would like to extend their gratitude to Hashim Nuru, owner of HELMIX export abattoir in Debre-Zeit, and his employees for their collaboration during sampling.

\section{Author details}

'Department of Veterinary Laboratory Technology, Faculty of Agriculture and Veterinary Sciences Ambo University, P.O.Box 19, Ambo, Ethiopia. ${ }^{2}$ College of Veterinary Medicine and Agriculture, Jimma University, P.O.Box 307, Jimma, Ethiopia. ${ }^{3}$ College of Veterinary Medicine, Samera University, P.O.Box 132, Samera, Ethiopia. ${ }^{4}$ Institute of Biotechnology, College of Natural and computational Sciences, Addis Ababa University, P.O. Box 1176, Addis Ababa, Ethiopia.

Received: 15 December 2013 Accepted: 2 October 2014

Published: 7 October 2014

\section{References}

1. Dubey JP: Toxoplasmosis of Animals and Humans. 2nd edition. Florida, U.S.A: CRC Press; 2010.

2. Butcher BA, Fox BA, Rommereim LM, Kim SG, Maurer KJ, Yarovinsky F, Herbert DR, Bzik DJ, Eric Y, Denkers EY: Toxoplasma gondii Rhoptry Kinase ROP16 activates STAT3 and STAT6 resulting in cytokine inhibition and arginase-1-dependent growth control. PLoS Pathog 2011, 7(9):1002236.

3. Torgerson PR, Macpherson CNL: The socioeconomic burden of parasitic zoonoses: global trends. Vet Parasitol 2011, 182:79-95.

4. Tenter AM, Heckerotha AR, Weiss LM: Toxoplasma gondii: from animals to humans. Int J Parasitol 2000, 30:1217-1258.

5. Dubey JP: Toxoplasmosis in sheep-The last 20 years. Vet Parasitol 2009, 163:1-14.

6. Torrey EF, Bartko JJ, Lun ZR, Yolken RH: Antibodies to Toxoplasma gondii in patients with schizophrenia: a meta-analysis. Schizophr Bull 2007, 33:729-736.

7. Palmer BS: Meta-analysis of three case controlled studies and an ecological study into the link between cryptogenic epilepsy and chronic toxoplasmosis infection. Seizure 2007, 2007(16):657-663.

8. Flegr J, Klose J, Novotná M, Berenreitterová M, Havlíček J: Increased incidence of traffic accidents in Toxoplasma-infected military drivers and 
protective effect $\mathrm{RhD}$ molecule revealed by a large-scale prospective cohort study. BMC Infect Dis 2009, 9:72.

9. Dubey JP, Tiao N, Gebreyes WA, Jones JL: A review of toxoplasmosis in humans and animals in Ethiopia. Epidemiol Infect 2012, 140:1935-1938.

10. Kassali $\mathrm{OB}$, Teklye B: Toxoplasmosis in sheep, goats and cattle in Central Ethiopia. Vet Res Commun 1989, 13:371-375.

11. Negash T, Tilahun G, Patton S, Prevot F, Dorchies P: Serological survey of toxoplasmosis in sheep and goats in Nazareth, Ethiopia. Rev Med Vet 2004, 55:486-487.

12. Teshale S, Dumetre A, Darde ML, Merga B, Dorchies P: Serological survey of toxoplasmosis in Ethiopia: prevalence and risk factors. Parasite 2007, 14:155-159.

13. Gebremedhin EZ, Agonafir A, Tessema TS, Tilahun G, Medhin G, Vitale M, Di Marco V, Cox E, Vercruysse J, Dorny P: Seroepidemiological study of ovine Toxoplasmosis in East and West Shewa zones of Oromia Regional State, Central Ethiopia. BMC Vet Res 2013, 9:117.

14. Zewdu E, Agonafir A, Tessema TS, Tilahun G, Medhin G, Vitale M, Di Marco V, Cox E, Vercruysse J, Dorny P: Seroepidemiological study of caprine toxoplasmosis in East and West Shewa zones, Oromia Regional State, Central Ethiopia. Res Vet Sci 2013, 94:43-48.

15. Yibeltal MM: Seroprevalence Study of Toxoplasmosis in Small Ruminants and Humans (HIV/AIDS Patient) in Selected District of South Wollo, Ethiopia, MSc. Thesis. Debre-Zeit, Ethiopia: Addis Ababa University, Faculty of Veterinary Medicine; 2008.

16. Tiao N, Darrington C, Molla B, Saville WJA, Tilahun G, Kwok OCH, Gebreyes WA, Lappin MR, Jones JL, Dubey JP: An investigation into the seroprevalence of Toxoplasma gondii, Bartonella spp., feline immunodeficiency virus (FIV), and feline leukaemia virus (FeLV) in cats in Addis Ababa, Ethiopia. Epidemiol Infect 2012, 141:1029-1033.

17. Tilahun G, Tiao N, Ferreira LR, Oliveira S, Verma SK, Kwok OCH, Molla B, Saville WJA, Medhin G, Kassa T, Aleme H, Gebreyes WA, Dubey JP: Seroprevalence of Toxoplasma gondii from free-range Chicken (Gallus domesticus) from Addis Ababa, Ethiopia. J Parasitol 2013, 99:740-741.

18. Gamble HR, Dubey JP, Lambillotte DN: Comparison of a commercial ELISA with the modified agglutination test for detection of Toxoplasma infection in the domestic pig. Vet Parasitol 2005, 128:177-181.

19. Shaapan RM, EL-Nawawi FA, Tawfik MA: Sensitivity and specificity of various serological tests for detection of Toxoplasma gondii infection in naturally infected sheep. Vet Parasitol 2008, 153:359-362.

20. De launta A, Habel R: Applied Veterinary Anatomy. Philadelphia, USA: WB Saunders; 1986.

21. Thrusfield M: Veterinary Epidemiology. 3rd edition. Oxford, UK: Blackwell Science Ltd; 2007.

22. Van der Puije WN, Bosompem KM, Canacoo EA, Wastling JM, Akanmori BD: The prevalence of anti-Toxoplasma gondii antibodies in Ghanaian sheep and goats. Acta Trop 2000, 76:21-26.

23. Dubey JP, Foreyt WJ: Seroprevalence of Toxoplasma gondii in Rocky Mountain big horn sheep (Ovis canadiansis). J Parasitol 2000, 86:622-623.

24. Demissie T, Tilahun G: Study on toxoplasmosis in sheep and goats in Debre Birhan and surrounding areas in Ethiopia. Bull Anim Hlth Prod Afr 2000, 50:138-147.

25. Samra NA, McCrindle CM, Penzhorn BL, Cenci-Goga B: Seroprevalence of toxoplasmosis in sheep in South Africa. J South Afr Vet Assoc 2007, 78:116-120.

26. Sharma SP, Baipoledi EK, Nyange JF, Tlagae L: Isolation of Toxoplasma gondii from goats with history of reproductive disorders and the prevalence of Toxoplasma and chlamydial antibodies. Onderstepoort J Vet Res 2003, 70(1):65-68.

27. Ramzan M, Akhtar M, Muhammad F, Hussain Fl, Hiszczynska-Sawicka E, Haq AU, Mahmood MS, Hafeez MA: Seroprevalence of Toxoplasma gondii in sheep and goats in Rahim Yar Khan (Punjab), Pakistan. Trop Anim Health Prod 2009, 41:1225-1229.

28. Hove T, Lind P, Mukaratirwa S: Seroprevalence of Toxoplasma gondii infection in goats and sheep in Zimbabwe. Onderstepoort J Vet Res 2005, 72:267-272.

29. Klun I, Djurković-Djaković O, Katić-Radivojević S, Nikolić A: Cross-sectional survey on Toxoplasma gondii infection in cattle, sheep and pigs in Serbia: Seroprevalence and risk factors. Vet Parasitol 2006, 135:121-131.

30. Sanad MM, Al-Ghabban AJ: Serological survey on Toxoplasmosis among slaughtered sheep and goats in Tabouk, Saudi Arabia. J Egypt Parasitol 2007, 37:329-340.
31. Romanelli PR, Freire RL, Vidotto O, Marana ER, Ogawa L, DePaula VS, Garcia JL, Navarro IT: Prevalence of Neospora caninum and Toxoplasma gondii in sheep and dogs from Guarapuava farms, Parana State, Brazil. Res Vet Sci 2007, 82:202-207.

32. Mason S, Quinnell JR, Smith JE: Detection of Toxoplasma gondii in lambs via PCR screening and serological follow up. Vet Parasitol 2010, 4:192-195.

33. Bisson AS, Maley CM, Rubaire-Akiiki J, Watling M: The seroprevalence of antibodies to Toxoplasma gondii in domestic goats in Uganda. Acta Trop 2000, 76:33-38.

34. Jittapalapong S, Sangvaranond A, Pinyopanuwat N, Chimnoi W, Khachaeram W, Koizum S, Maruyama S: Seroprevalence of Toxoplasma gondii infection in domestic goats in Satun province, Thailand. Vet Parasitol 2005, 127:17-22.

35. Barakat AM, Abdelaziz MM, Fadaly M: Comparative diagnosis of toxoplasmosis in Egyptian small ruminants by indirect hemagglutination assay and ElISA. Global Veterinaria 2009, 3:9-14.

36. Dubey JP: Toxoplasmosis - a waterborne zoonosis. Vet Parasitol 2004, 26:57-72.

37. Innes EA, Bartley PM, Buxton D, Katzer F: Ovine toxoplasmosis. Vet Parasitol 2009, 136:1884-1887.

38. Opsteegh $M$, Teunis $P$, Mensink M, Zuchner L, Titilincu A, Langelaar M, van der Giessen J: Evaluation of ELISA test characteristics and estimation of Toxoplasma gondii seroprevalence in Dutch sheep using mixture models. Prev Vet Med 2010, 96:232-240.

39. Gebremedhin EZ, Abebe HA, Tessema TS, Tullu DK, Medhin G, Vitale M, Di Marco V, Cox E, Dorny P: Seroepidemiology of Toxoplasma gondii infection in women of child-bearing age in Central Ethiopia. BMC Infect Dis 2013, 13:101.

\section{doi:10.1186/1756-0500-7-696}

Cite this article as: Gebremedhin et al: Seroprevalence and risk factors of Toxoplasma gondii infection in sheep and goats slaughtered for human consumption in Central Ethiopia. BMC Research Notes 2014 7:696.

\section{Submit your next manuscript to BioMed Central and take full advantage of:}

- Convenient online submission

- Thorough peer review

- No space constraints or color figure charges

- Immediate publication on acceptance

- Inclusion in PubMed, CAS, Scopus and Google Scholar

- Research which is freely available for redistribution

Submit your manuscript at www.biomedcentral.com/submit
C Biomed Central 